\title{
Accurate DRL performance in the pigeon: Comparison between perching and treadle pressing
}

\author{
HELGA LEJEUNE and PIERRE JASSELETTE \\ University of Liège, Liège, Belgium
}

\begin{abstract}
Homing pigeons were reinforced for emitting a perching response according to differentialreinforcement-of-low-rate (DRL) schedules. The spacing requirement between successive perchings was progressively increased by $1-\mathrm{sec}$ steps up to $70 \mathrm{sec}$ and then abruptly decreased to 60 , 40 , and 20 sec. IRT/OP (interresponse time/opportunity) functions were maximal near the time of reinforcement. The coefficients of variation of the IRT distributions (ratio between the interquartile range and median IRT) fluctuated around .32, testifying for equivalent levels of adjustment throughout the critical IRT range. The ratio between reinforced and total IRTs ranged between .90 and .20 . These data contrast with the performance of another group of pigeons reinforced for a treadle-pressing response according to DRL schedules (flatter IRT/OP functions, high coefficients of variation, and low efficiencies). Despite these differences in temporal regulation between perching and treadle-pressing DRL, response rates and reinforcement rates followed the same trend in both cases: they decreased as schedule value increased. The DRL perching results are similar to previous results obtained in the same species when perching duration was reinforced.
\end{abstract}

Pigeons fail at spacing keypecks when requirements exceed 20 or $30 \mathrm{sec}$ (Staddon, 1965; for reviews, see Kramer \& Rilling, 1970; Richelle \& Lejeune, 1980). The use of treadle pressing, a response topographically different from the keypeck, led to lower response rates and higher proportions of reinforced IRTs (Hemmes, 1975; Mantanus, Julien, \& Pitz, 1977; Richardson \& Clark, 1976). Nevertheless, the improvement in the efficiency of behavior was not due to an improvement in the temporal regulation of responses as measured by IRT/OP (interresponse time/opportunity) functions (Richardson \& Clark, 1976). Higher reinforcement rates for treadle pressing were due to a flattening of the IRT distribution (Mantanus et al., 1977) and to extremely long IRTs not found with keypecking (Richardson \& Clark, 1976; see also Hemmes, 1975). However, both operants in differential reinforcement of low rate (DRL) follow the same function: response and reinforcement rates decrease as the DRL schedule requirement increases (Richardson \& Clark, 1976).

These data do not mean that pigeons lack the capacity to estimate time, as evidenced by experiments on the discrimination of stimulus duration (e.g., Stubbs, 1968). Pigeons are also capable of precisely timing the durations of their own behaviors when a perching response is used.

The authors wish to thank Professor Marc N. Richelle for valuable comments on the manuscript. They acknowledge the help of students and of Judit Nagy in conducting part of the experiment. Reprint requests may be sent to $H$. Lejeune, Experimental Psychology Laboratory, University of Liège, B32, Sart-Tilman, B-4000, Liège, Belgium.
Up to a $40-$ or $50-$ sec requirement, median perching durations approximated the required response durations and efficiencies remained high. Response duration distributions peaked close to the schedule criteria and comparable dispersions showed up throughout the critical response durations range (Lejeune \& Richelle, 1982).

This contrast between differential reinforcement of perching duration and treadle-pressing or keypecking DRL might be due to the difference in the schedule used, rather than to the response factor. A comparison with DRL perching was needed in order to disentangle the variables at stake, as suggested by Fantino (1984). In the present experiment, pigeons were shaped to emit a perching response, that is, to hop on a perch and then step quickly off. This response was then put under the control of a DRL schedule. Instead of spacing keypecks or treadle presses, the birds had to space perchings. Another group of birds was trained on a DRL treadle-pressing schedule, to allow for comparison between performances obtained in the same schedule of reinforcement with two types of gross motor behavior that differ from keypecking.

\section{METHOD}

\begin{abstract}
Subjects
Eight adult homing pigeons were housed individually and maintained at $90 \%$ of their free-feeding weight. They had had experience with fixed-interval (FI) and fixed-time (FT) schedules (Lejeune \& Jasselette, 1985), but were naive with respect to the operant response studied in the present experiments. Four pigeons (P7, P8, P9, and P12), which had performed a treadle-pressing response in the earlier experiment, were trained to the perching response. The remaining pigeons (P1, P2, P4, and P5), which had pecked at a key in the earlier experiment, were trained to press a treadle with their feet.
\end{abstract}


There was a period of 4 months between the end of the previous experiment and the beginning of the present one.

\section{Apparatus}

The conditioning chambers used in the present experiment were two transparent Plexiglas cubicles $(50 \times 40 \times 40 \mathrm{~cm})$ with the left side panel painted dark green. They were housed in soundattenuating enclosures. The food aperture $(5 \times 6.5 \mathrm{~cm})$ was located in the middle of the green panel, $5 \mathrm{~cm}$ above the floor. Gerbrands grain dispensers were located behind the food apertures. In one of the cubicles, a white Plexiglas treadle $(5 \times 7 \mathrm{~cm})$, requiring $50 \mathrm{~g}$ or $.5 \mathrm{~N}$ force and $1 \mathrm{~cm}$ excursion, was placed to the right of the food aperture, $10 \mathrm{~cm}$ apart from it and $3 \mathrm{~cm}$ above the floor. The other cubicle was equipped with a metal perch protruding $16 \mathrm{~cm}$ from the rear wall and located $13 \mathrm{~cm}$ above the floor. A weight of $180 \mathrm{~g}$ or $1.8 \mathrm{~N}$ (less than the average weight of the subjects, which was $422 \mathrm{~g}$ ) was needed to depress the perch and close a microswitch located behind the cage wall. The distance between the perch and the food tray approximated $26 \mathrm{~cm}$. The cubicles were illuminated by $60-\mathrm{W}$ white bulbs located at the ceiling of the soundattenuating enclosures. Each enclosure had a one-way observation window.

\section{Procedure}

DRL perching. Reinforcement (5-sec access to mixed grain) was made contingent upon the pigeons' hopping onto the perch, rather than upon their stepping off, in order to lure the pigeons off the perch as soon as they had hopped on it. During training only, if the birds waited for more than $2 \mathrm{sec}$ before stepping off, grain presentation was interrupted and they got no reinforcement.

The perching response was obtained at the first shaping session. The birds were then exposed to a continuous reinforcement (CRF) schedule for three daily sessions (limited to 25 reinforcements). From the CRF schedule on, the experiment was automatically controlled and the duration of perching was no longer taken into account as a condition for reinforcement. The birds were then exposed to the DRL schedule and the minimum delay required between responses ( $1 \mathrm{sec}$ ) was increased by 1 -sec steps every fourth session, except at delays of $10,20,30,40,50,60$, and $70 \mathrm{sec}$, for which exposure to the schedule extended over 20 or 10 (at $70 \mathrm{sec}$ ) sessions. A second exposure followed. The birds were abruptly shifted to DRL $60 \mathrm{sec}$ for 3 sessions, then to DRL $40 \mathrm{sec}$ for 6 sessions, and finally to DRL $20 \mathrm{sec}$ for 10 sessions. In each case, sessions were limited to 25 reinforcements or $1 \mathrm{~h}$, whichever came first, and IRTs were measured between successive perchmicroswitch closures. The whole experiment extended over 347 conditioning sessions.

DRL treadle pressing. The treadle-pressing birds were exposed to the same sequence of schedules as the perching birds, except that the highest DRL delay studied was $40 \mathrm{sec}$, and no second determination was made at lower schedule values. The treadle-pressing experiment extended over 188 sessions. Reinforcement duration was $4 \mathrm{sec}$, that is, $1 \mathrm{sec}$ less than for the perching subjects. This difference was intended to equate the real access time to the grain dispenser, the treadle being located at the right side of the food aperture and therefore immediately accessible. As for the perching birds, IRTs were in every case timed between the successive closures of the treadle microswitch.

Analysis of Data. The overall response rate (responses per minute), the reinforcement rate (reinforcements per hour), the efficiency ratio (number of reinforced IRTs/total number of IRTs), the median IRTs, the interquartile range of IRTs, the absolute and relative frequency distributions of IRTs in successive time bins (12 below and 12 above the critical delay), and the conditional probabilities of IRTs (IRTs per opportunity; Anger, 1956) were computed from the recorded data. For the perching subjects, at DRL 10 and $20 \mathrm{sec}$ only, absolute IRT frequencies that showed up in the first time bin were discarded from data analysis. These IRTs were not due to successive perching responses (the width of one bin at $20 \mathrm{sec}$ is equal to $1.66 \mathrm{sec}$ ), as direct observation confirmed. They were due to mechanical artifacts as the birds jumped on or stepped off the perch. These artifacts, very rare in Birds P8 and P12, never represented more than $14 \%$ of the relative IRT frequencies in Bird P7. They decreased progressively as the birds' skill in stepping on and jumping off the perch developed.

Data from the last three sessions at the 10-, 20-, 30-, 40-, 50-, 60 -, and 70-sec schedule values was analyzed. For the perching birds, the duration of perch-microswitch closures was also recorded over the last three sessions at the 20-, 40-, 50-, 60-, and 70-sec schedule values. The experiments were monitored by Rockwell AIM 65 computers. Data analysis was made on Rockwell AIM 65 and Apple II computers. Cumulative records were obtained for every session throughout the experiment. Examination of the cumulative records showed that behavior was stable over the last three sessions at each schedule value. The pigeons were run 6 days a week and were observed frequently throughout the experiments.

\section{RESULTS}

Figure 1 presents overall response rates of perching (left side) and treadle-pressing (right side) birds as a function of DRL schedule value. Open symbols present second-
PERCH

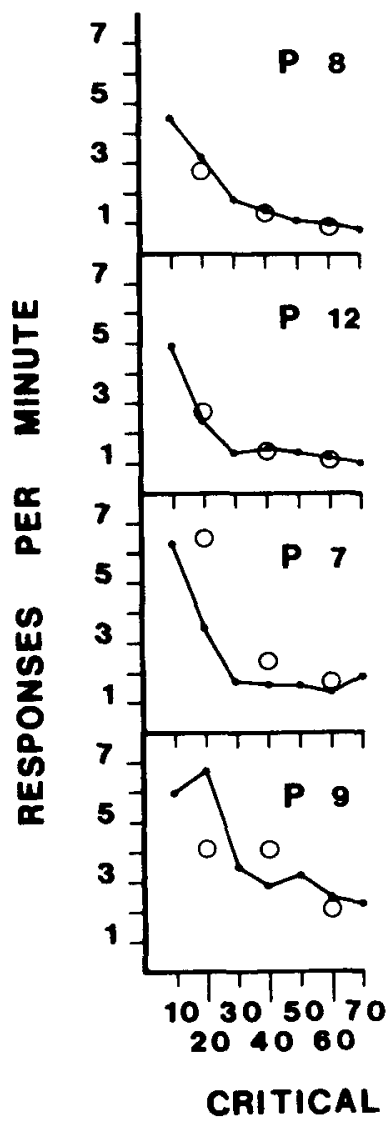

TREADLE

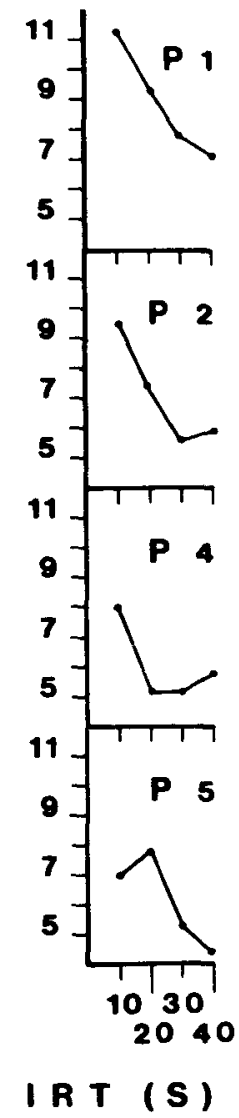

Figure 1. Individual response rates for the perching responses (left column) and the treadle-pressing responses (right column) as a function of DRL schedule value. Open symbols present second-exposure data at DRL 20, 40, and 60 sec. Each data point was computed over the last three sessions at each critical IRT. Notice that different arithmetic scales were used for the ordinates. 


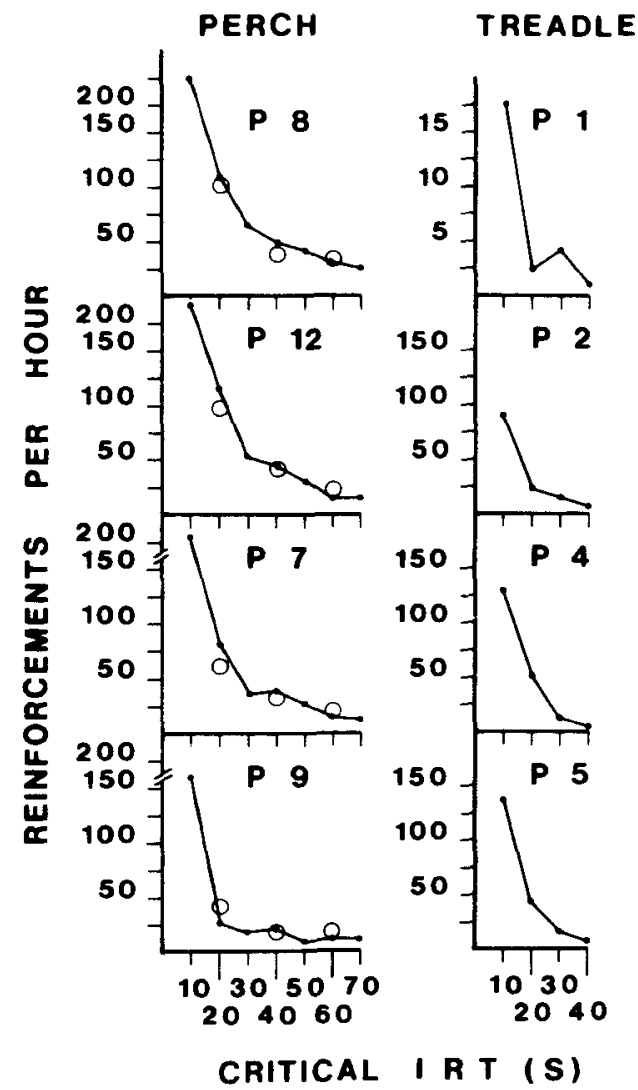

Figure 2. Individual reinforcement rates for the perching response (left column) and the treadle-pressing response (right column) as a function of DRL schedule value. For other details, see legend of Figure 1.

exposure data at DRL 20, 40, and $60 \mathrm{sec}$ for the perching birds. Response rates were, at each schedule value, higher for treadle-pressing subjects. They tended to decrease in both groups as a function of increasing schedule value. Second-determination data follow the same trend and were similar to those from the first-exposure values in Birds P8 and P12. Higher response rates at second exposure for Bird P7 at 20 and $40 \mathrm{sec}$ were due to progressive shifting from the perching response to a "neck pushing" response. For Bird P9, such a shift had occurred much earlier, between DRL 10 and $20 \mathrm{sec}$. Typically, these subjects stood next to the perch, extended their necks over it, and pushed it down. As a consequence, response rates increased and the cumulative records presented stairlike features, due to several burst-like rapid neck pushings. This neck-pushing behavior occurred together with perching in the same session and persisted until the end of the experiment once it had appeared. The lower response rate at the DRL 20-sec exposure for Bird P9 was due to the development of a collateral behavior never presented before (rapid pacing back and forth in the left part of the conditioning cubicle).

Figure 2 shows reinforcement rates (reinforcements per hour) of the perching (left side) and treadle-pressing sub- jects (right side) as a function of DRL schedule value. As in Figure 1, open symbols present second-exposure data at 20-, 40-, and 60-sec values. Reinforcement rates were higher for the perching birds. They decreased in both groups as a function of increasing schedule values. Second-exposure data match very closely the firstexposure data.

Relative IRT frequency distributions of perching and treadle-pressing birds were compared at DRL 10, 20,30, and $40 \mathrm{sec}$ with the Kolmogorov-Smirnov test (twotailed). Differences are significant at $p \leq .001$ at each schedule value.

Figures 3 and 4 present the response probability distributions for each subject under all DRL values (IRT/OP; Anger, 1956). For perching and treadle pressing, response probabilities increase as time since the last response elapses. For most cases, the range between lowest and highest response probabilities is greater with the perch-

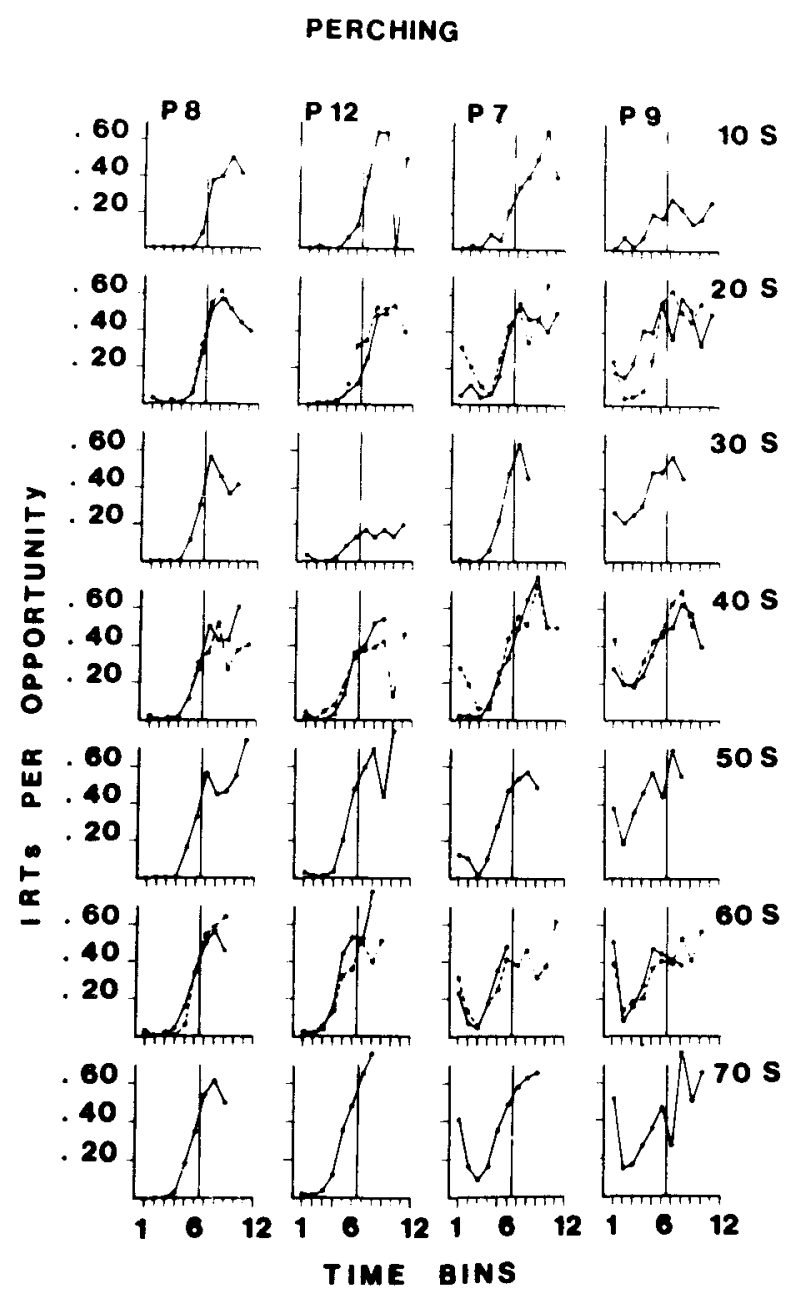

Figure 3. IRT/OP distributions for the perching response. Each bin is one-sixth of the schedule value. The rightmost point in each function is the 11th bin or the last bin with at least 40 opportunities. All IRTs to the right of the vertical line were reinforced. Broken lines present second-determination data. 


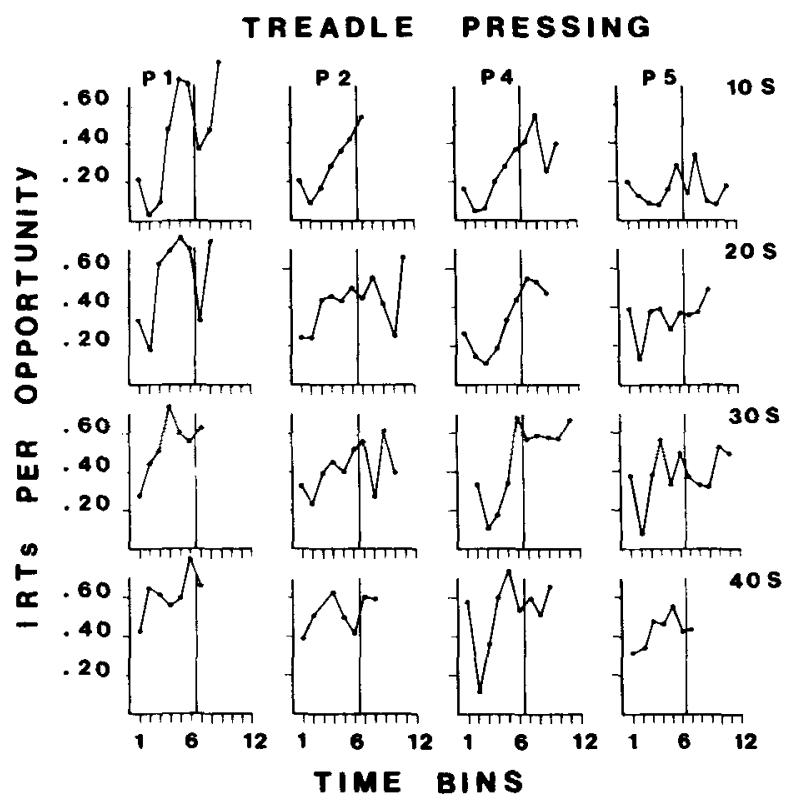

Figure 4. IRT/OP distributions for the treadle-pressing response. For other details, see legend of Figure 3.

ing response. Bird P12 at $30 \mathrm{sec}$ developed sequences of iterative head bowings between perch responses. This behavior chain extended progressively in time, to the point that some IRTs far exceeded the schedule requirement. This head bowing remained a constant in that bird's behavior, but distorted the IRT/OP distribution only at DRL $30 \mathrm{sec}$. Response probabilities in the lowest bins are close to 0 for the perching response (except when neck-pushing responses were emitted; see Bird P7 from $50 \mathrm{sec}$ on and Bird P9 from $20 \mathrm{sec}$ on). They are much higher for the treadle-pressing subjects. Response probabilities change as a function of schedule value for the treadle-pressing response: a progressive flattening develops, due to the increase of probabilities in the lowest bins as DRL value increases. Maximal rise in probability is highest close to DRL criterion with perching. For treadle pressing, maximal increase in probability, as well as peak probability, tends to fall short of the schedule value as it increases.

Figure 5 presents median interresponse times as a function of critical IRTs. As can be seen in the left column, perching clearly was controlled by the schedule requirement up to 60 or $70 \mathrm{sec}$ in Birds P7, P8, and P12. The median IRT of Bird P9 matched those of the other subjects at DRL $10 \mathrm{sec}$. After shifting to the neck-pushing response, the median IRT remained low at the other schedule requirements. The slight improvements seen in some cases were due to the development of collateral behavior: pacing at DRL $20 \mathrm{sec}$ or "long"' perching behavior between neck responses. Typically, after a neck pushing, Bird P9 jumped on the perch, preened or sometimes flapped its wings, stepped down, and emitted one or several rapid neck pushings. These collateral "long perchings" were also observed in Bird P7 from $50 \mathrm{sec}$ on in the ascending series and at second determination. In the case of Bird P7, the late appearance of neck pushing preserved the direct relationship between median IRT and critical IRT. Median IRTs paralleled the diagonal line, but at a distance. The two median IRTs plotted for Bird P12 at the 30-sec schedule value were computed with (upper point) or without (lower point) the frequency of the last bin (see comments about Figure 3). Observing birds in front of the perch before they stepped on it showed that movements of the feet (stamping one foot and then the other) and of the neck (stretching forward and upward) preceded jumping onto the perch proper. Both behaviors were particularly evident in Birds P7 and P9 (with the already described consequence).

In the middle column of Figure 5, it can be seen that median IRTs obtained with the treadle-pressing response (Birds P1, P2, P4, and P5) lag behind the schedule requirement, even at $10 \mathrm{sec}$. No clear-cut increase in the central tendency of the IRTs is evident. Bird P4, which improved slightly up to $30 \mathrm{sec}$, did not maintain this improvement at the 40 -sec requirement. Treadle-pressing subjects remained in front of the treadle and emitted sequences of response bursts, the foot remaining on the treadle for a train of successive pressings, or briefly spaced responses, separated by the foot's being put on the floor. For the sake of comparison, the right column of Figure 5

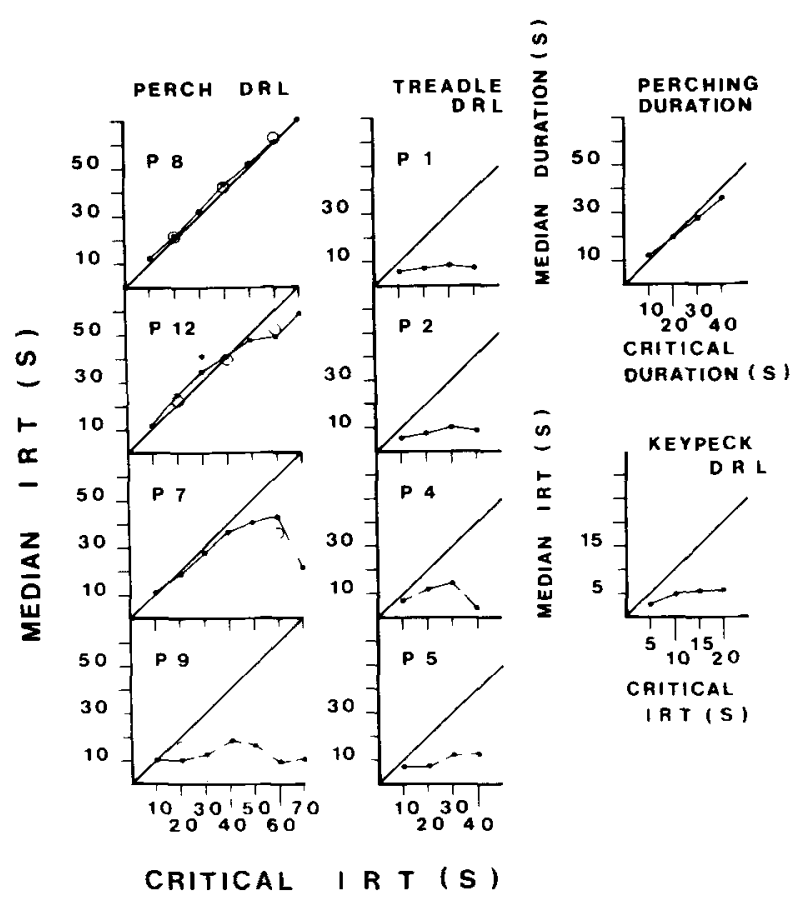

Figure 5. Median interresponse times (IRTs) of the perching response (left column) and the treadle-pressing response (middle column) as a function of critical IRT for individual subjects. Each data point was computed over the last three sessions at each schedule value. Open symbols present second-exposure data at DRL 20, 40 , and 60 sec. The right column presents average data from a previous experiment comparing perching-duration reinforcement (upper part) and keypeck DRL (lower part) in pigeons (Lejeune \& Richelle, 1982). 
presents average data from a previous experiment (reinforcement of perching duration and keypecking DRL; Lejeune \& Richelle, 1982).

Table 1 presents, for all subjects, the ratio between interquartile range and median IRT at each schedule value. This coefficient of variation remained low and was approximately constant (around .32) over the range of critical delays for the birds emitting the perching response. The coefficent took higher values after neck pushing appeared in Birds $\mathrm{P} 7$ and $\mathrm{P} 9$, and for each treadle-pressing subject (mean $=1.38$ ).

Table 2 gives the efficiency ratios (reinforced IRTs divided by total IRTs) for all subjects at each schedule requirement. Birds emitting the perching response (P7, $\mathrm{P8}$, and P12) clearly contrasted with those emitting the treadle-pressing response (P1, P2, P4, and P5). Even though, at DRL $10 \mathrm{sec}$, the efficiency ratios of Birds P4 and P5 were above .25, they fell to less than .10 for all treadle-pressing birds at DRL 30 and $40 \mathrm{sec}$. They were especially low for Bird P1. The effect of the transition from perching to neck pushing was again evident in Birds P7 and P9, whose efficiencies dropped.

Taken together, these data tend to show that reinforcements earned by the perching subjects were not a byproduct of too-long IRTs, but depended upon an accurate regulation of the responses (median IRTs adjusted to the critical delay, low and constant coefficient of variation). It remained to be shown that, due to extended training and/or increasing DRL requirements, the perching response had not drifted from a "brief" perching, as it was selected by hand-shaping, toward longer perchings that would render this experiment close to the perching duration experiment reported earlier (Lejeune \& Richelle, 1982). It should be remembered here that the DRL schedule was not designed to select brief perchings per se and that IRTs were timed between successive perch-microswitch closures. It could therefore be argued that IRTs starting

Table 1

Coefficients of Variation

(Ratio Between the Interquartile Range and Median IRT of the IRT Distribution)

\begin{tabular}{|c|c|c|c|c|c|c|c|c|}
\hline \multirow{2}{*}{$\begin{array}{c}\text { DRL } \\
\text { Values } \\
\text { (in Seconds) }\end{array}$} & \multicolumn{4}{|c|}{ Perching Subjects } & \multicolumn{4}{|c|}{$\begin{array}{c}\text { Treadle-Pressing } \\
\text { Subjects }\end{array}$} \\
\hline & P8 & $\mathbf{P 1 2}$ & P7 & P9 & P1 & $\mathbf{P 2}$ & P4 & P5 \\
\hline 10 & .28 & .24 & .36 & .61 & .62 & 1.06 & .70 & 1.28 \\
\hline 20 & .26 & .28 & .44 & $.98 *$ & 1.14 & 1.08 & 1.22 & 1.48 \\
\hline 30 & .26 & $\begin{array}{l}.52 \dagger \\
.70\end{array}$ & .28 & $1.34 *$ & 1.06 & 1.40 & 1.26 & 1.30 \\
\hline 40 & .30 & .34 & .40 & $1.40^{*}$ & 1.26 & 1.36 & 4.54 & 1.34 \\
\hline 50 & .24 & .28 & $.84 *$ & $1.52 *$ & & & & \\
\hline 60 & .30 & .44 & $.94 *$ & $4.14^{*}$ & & & & \\
\hline 70 & .30 & .36 & $2.46^{*}$ & $4.04 *$ & & & & \\
\hline $60 \mathrm{~B}$ & .26 & .44 & $2.30 *$ & $2.02 *$ & & & & \\
\hline $40 \mathrm{~B}$ & .32 & .46 & $1.16^{*}$ & $2.42 *$ & & & & \\
\hline $20 \mathrm{~B}$ & .22 & .30 & $1.94 *$ & $.92 *$ & & & & \\
\hline
\end{tabular}

Note-Each value is computed over the last three sessions at a given schedule requirement. ${ }^{*}$ With neck-pushing responses. $†$ Coefficient of variation computed without taking into account the frequency of IRTs in the last bin (see text). (B = second determination.)
Table 2

Efficiency Ratios

(Ratios Between Reinforced IRTs and Total IRTs)

\begin{tabular}{ccccccccccc}
\hline \multirow{2}{*}{$\begin{array}{c}\text { DRL } \\
\text { Values }\end{array}$} & \multicolumn{4}{c}{ Perching Subjects } & & \multicolumn{4}{c}{$\begin{array}{c}\text { Treadle-Pressing } \\
\text { Subjects }\end{array}$} \\
\cline { 2 - 5 } \cline { 7 - 9 } (in Seconds) & P8 & P12 & P7 & P9 & & P1 & & P2 & P4 & P5 \\
\hline 10 & .90 & .80 & .64 & .54 & .025 & .15 & .26 & .33 \\
20 & .64 & .78 & .38 & $.07^{*}$ & .0039 & .049 & .16 & .091 \\
30 & .59 & $.61 \dagger$ & .36 & $.07^{*}$ & .0085 & .042 & .041 & .048 \\
& & .74 & & & & & & \\
40 & .61 & .49 & .41 & $.11^{*}$ & .0024 & .12 & .14 & .030 \\
50 & .55 & .32 & $.25^{*}$ & $.04^{*}$ & & & & \\
60 & .51 & .20 & $.17^{*}$ & $.08^{*}$ & & & & \\
70 & .50 & .26 & $.12^{*}$ & $.08^{*}$ & & & & \\
$60 \mathrm{~B}$ & .57 & .34 & $.20^{*}$ & $.12^{*}$ & & & & \\
$40 \mathrm{~B}$ & .57 & .48 & $.22^{*}$ & $.07^{*}$ & & & & \\
$20 \mathrm{~B}$ & .62 & .60 & $.19^{*}$ & $.15^{*}$ & & & & \\
\hline
\end{tabular}

Note-Each value is computed over the last three sessions at a given schedule requirement. ${ }^{*}$ With neck-pushing responses. + Efficiency ratio computed without taking into account the frequency of IRTs in the last bin (see text). (B = second determination.)

with a nonreinforced response may have been filled in by the birds' staying on the perch before stepping off and hopping back on it. Indeed, at higher schedule values, the subjects would not have been "punished" for lengthening the first perching response of an IRT, because no time would be lost, from an economical point of view, so long as the lengthening did not exceed the required IRT. Figure 6 presents the median and mean perch-response durations for Birds P8, P12, P7, and P9, computed over the last three sessions at the 20-, 40-, 50-, 60-, and 70sec schedule requirements. In every case, median response durations remained low. Furthermore, with the exceptions of Birds P7 (at 60 and $70 \mathrm{sec}$ ) and P9, mean perching durations remained under $5 \mathrm{sec}$. Temporal regulation of behavior cannot be accounted for in terms of response durations not controlled by the DRL schedule: they represent only a small fraction of the IRTs.

\section{DISCUSSION}

Pigeons performed accurately on a DRL schedule up to $70 \mathrm{sec}$ when a perching response was used. IRT distributions were well peaked at each schedule requirement and central tendencies (modal or median IRT) were located close to the critical IRT value. IRT/OP functions confirmed these points and showed a maximum increase in response probability close to the schedule criteria. Furthermore, coefficients of variation (ratio between interquartile range and median IRT) remained low (around .32) and response durations remained brief (median duration under $3 \mathrm{sec}$, mean duration under $5 \mathrm{sec}$ ) over the range of DRL values studied.

On the other hand, treadle-pressing subjects presented a mode in the lower IRT range, central tendency indices (median or modal IRTs) that did not follow schedule requirements up to $40 \mathrm{sec}$, and a flattening of IRT/OP functions as DRL delay increased. The results obtained with treadle-pressing were not due to the absence of schedule 


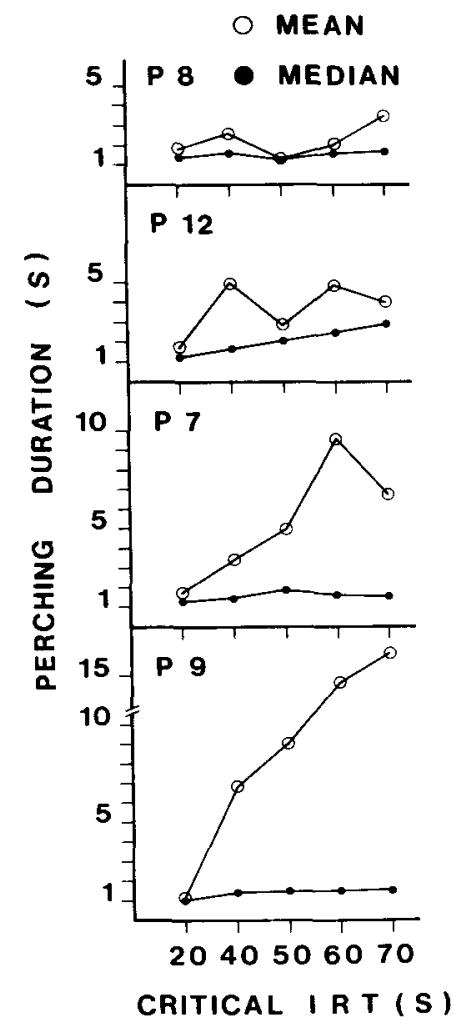

Figure 6. Median and mean perch-response durations as a function of critical IRT for individual subjects submitted to the DRL perching-reinforcement schedule. Each data point was computed over the last three sessions at each schedule value.

control: as a rule, response and reinforcement rates decreased with both treadle pressing and perching as the critical delay increased.

These results demonstrate that the response factor and not the schedule factor (or both) accounts for the difference first observed between perching-duration reinforcement and DRL keypecking reinforcement (Lejeune \& Richelle, 1982). Results obtained with reinforcement of perching duration and perching DRL were similar (see Figure 5). The important point is that these similar results were recorded with differential reinforcement of response duration (DRRD) and without (DRL) a response duration contingency.

Minor differences between perching-duration and DRLperching reinforcement need further investigation. Extinction was not observed in the present experiment, in contrast to the abrupt deterioration of performance with critical values between 40 and $55 \mathrm{sec}$ (depending upon the subject) reported in the perching-duration experiment (Lejeune \& Richelle, 1982). Tentatively, this difference seems related to the suggestions of Platt $(1979$, p. 9) and Catania (1970, pp. 19-20) that increasing the schedule requirement leads to extinction with response-duration reinforcement but not with DRL or differential reinforcement of long latencies (DRLL).

As to within- and intersubject variability, Platt, Kuch, and Bitgood (1973) argued that more homogeneous be- havior should be obtained with a response-duration reinforcement schedule that specifies what the subjects have to do during the requirement, as opposed to latency or IRT reinforcement that specifies only what the subjects have not to do during latencies or IRTs. Indeed, "idiosyncratic or unstable response strategies"' (Platt, 1979, p. 6) did occur in the present experiment, in contrast to the homogeneous behavior recorded when perching duration was reinforced (Lejeune \& Richelle, 1982). First, very long IRTs appeared at DRL $30 \mathrm{sec}$ in Bird P12, due to the development of a head-bowing sequence during IRTs. Second, shifting from a perching response to a neckpushing response occurred in Birds P7 (from $50 \mathrm{sec}$ on) and P9 (at $20 \mathrm{sec}$ ). The origin of this shifting can be traced back to the behavior displayed by the birds before jumping on the perch: foot stamping and neck stretching over the perch. If neck stretching results several times in reinforcement, conditions are set for a shift from perching to neck pushing. The recording of neck pushing could have been avoided by putting a heavier counterweight on the perch in order to increase the force requirement. However, if neck pushing is related to an increasing level of motor excitation as time elapses since the last perching response, some actometric recording of that type of behavior could lead to further experimental developments (see, e.g., Killeen, 1975).

In their natural environment, pigeons perch for longer times when resting. Two components can be isolated: the perching in itself, and its duration. Therefore, it could be argued that the perching response in the DRL schedule has an arbitrary feature (its briefness), which is not present in the perching-duration response studied in Lejeune and Richelle's (1982) experiment. In the present experiment, the schedule requirements set no limit on the duration of perching (except an indirect one-when reinforcement was presented, the birds had to step off quickly in order to obtain grain; see also comments about Figure 6); it is worth noting that no drifting toward longer response durations was observed as the critical delay increased. A straightforward explanation would link the persistence of brief perching to the high efficiency of behavior, even at 60- and 70-sec DRL. Further experimentation is needed to clarify that point.

Results described for treadle-pressing DRL are similar in two ways to those described by Richardson and Clark (1976) for a comparable DRL range (5-60 sec). First, Richardson and Clark's IRT distributions were monotonically decreasing, without a clear-cut mode at higher IRT values, as was the case in the present experiment. Second, response and reinforcement rates decreased in both experiments when schedule requirements increased (Hemmes, 1975, noticed the same trend for treadlepressing birds over a DRL 5-35-sec range). The higher reinforcement rates in Richardson and Clark's experiment resulted "from extremely long IRTs," which we did not observe in the present experiment, and were "not the result of a more precise temporal discrimination" (p. 254). 
The important result of the present experiment is that temporal regulation was more precise with the perching response than with the treadle-pressing response. The fact that a difference in the quality of adjustment was obtained with two responses, each of which pertains to the category of more or less gross motor behavior and is not linked to food-seeking or eating activities, stresses the peculiar status of the perching response and the importance of response factors in unveiling the capacity of pigeons to precisely time their motor behavior.

\section{REFERENCES}

ANger, D. (1956). The dependence of interresponse times upon the relative reinforcement of different interresponse times. Journal of Experimental Psychology, 52, 145-161.

CATANia, A. C. (1970). Reinforcement schedules and psychophysical judgment. In W. N. Schoenfeld (Ed.), The theory of reinforcement schedules (pp. 1-42). Englewood Cliffs, NJ: Prentice-Hall.

Fantino, E. (1984). Timing in animal learning and behavior: Discussion paper. In J. Gibbon \& L. Allan (Eds.), Timing and time perception (Annals of the New York Academy of Sciences, Vol. 423, pp. 292-295).

Hemmes, N. S. (1975). Pigeons' performance under differential reinforcement of low rate schedules depends upon the operant. Learning \& Motivation, 6, 344-357.

KILLEEN, P. (1975). On the temporal control of behavior. Psychological Review, 82, 89-115.

Kramer, G., \& Rilling G. M. (1970). Differential reinforcement of low rates: A selective critique. Psychological Bulletin, 74, 225-254.
Lejeune, H., \& JASSe lette, P. (1985). Fixed interval and fixed time treadle pressing in the pigeon: A comparison with FI and FT keypecking. Behavioural Processes, 11, 131-152.

LEJEUNE, H., \& RicheLle, M. (1982). Differential reinforcement of perching duration in the pigeon: A comparison with DRL keypecking. Behaviour Analysis Letters, 2, 49-57.

Mantanus, H., Julien, I., \& Pitz, I. (1977). Comparaison de deux réponses operantes chez le pigeon. Psychologie française, 22, 61-68.

PlatT, J. R. (1979). Temporal differentiation and the psychophysics of time. In M. D. Zeiler \& P. Harzem (Eds.), Advances in analysis of behaviour: Reinforcement and the organisation of Behaviour (Vol. 1, pp. 1-29). New York: Wiley.

Platt, J. R., Kuch, D. O., \& Bitgood, S. C. (1973). Rats' lever press durations as psychological judgments of time. Journal of the Experimental Analysis of Behavior, 19, 239-250.

RiChardson, W. K., \& CLARK, D. B. (1976). A comparison of the keypeck and treadle-press operants in the pigeon: Differentialreinforcement-of-low-rate schedule of reinforcement. Journal of the Experimental Analysis of Behavior, 26, 237-256.

Richelle, M., \& Lejeune, H. (1980). Time in animal behaviour. OXford and New York: Pergamon Press.

StaddoN, J. E. R. (1965). Some properties of spaced responding in pigeons. Journal of the Experimental Analysis of Behavior, 8, 19-27. STuBBS, D. A. (1968). The discrimination of stimulus duration by pigeons. Journal of the Experimental Analysis of Behavior, 11, 223-238.

(Manuscript received November 18, 1985; revision accepted for publication February $27,1986$. 